\title{
Riscos ocupacionais do/no motorista de carreta e seus impactos na gestão da saúde e
}

\section{segurança}

\author{
Occupational risks of/on the reel driver and its impacts on health and safety management \\ Riesgos ocupacionales del conductor del remolque y sus impactos en la gestión de la seguridad y la \\ salud
}

Recebido: 29/09/2021 | Revisado: 05/10/2021 | Aceito: 13/10/2021 | Publicado: 15/10/2021

Carine de Oliveira Gomes

ORCID: https://orcid.org/0000-0002-8614-3752 Universidade Federal de Itajubá, Brasil

E-mail: carinegomes.o@gmail.com

Geraldo Fabiano de Souza Moraes

ORCID: https://orcid.org/0000-0003-3611-3931 Universidade Federal de Itajubá, Brasil E-mail: geraldofsmoraes@gmail.com

Luiz Felipe Silva

ORCID: https://orcid.org/0000-0002-3174-9984 Universidade Federal de Itajubá, Brasil

E-mail: lfelipe.unifei@gmail.com

Davidson Passos Mendes

ORCID: https://orcid.org/0000-0002-5298-9960 Universidade Federal de Itajubá, Brasil E-mail: davidsonpmendes@gmail.com

\begin{abstract}
Resumo
O artigo tem por pretensão fazer revelar a atividade de trabalho dos motoristas de carreta em busca de se entender a forma como a organização do trabalho impacta na possibilidade de regulação desses trabalhadores. Utilizou-se do aporte teórico da Ergonomia e da Ergologia, em um estudo transversal descritivo, desenvolvido em três etapas: aplicação de questionário, entrevistas semiestruturadas e uma auto confrontação cruzada, por via remota. Os resultados mostram que há uma ausência/deficiência na gestão da saúde e segurança no trabalho, que é complexa por envolver diversas empresas para as quais os motoristas prestam serviços. É necessário trabalhar essa gestão em todos os setores, criar um campo de regulação para o motorista, que trabalha sobre pressão de produção, com jornadas excessivas, dificuldade para carga e descarga, sendo necessário oferecer um suporte adequado e condições melhores de trabalho, com uma logística eficiente e um atendimento adequado, a fim de evitar os riscos de adoecimentos.
\end{abstract}

Palavras-chave: Motoristas; Ergonomia; Ergologia; Riscos ocupacionais; Saúde do trabalhador.

\begin{abstract}
The paper intends to reveal the work activity of truck drivers in order to understand how the organization of work impacts on the possibility of regularization of workers. The theoretical contribution of Ergonomics and Ergology was used in a cross-sectional descriptive study, developed in three stages: application of questionnaire, declared semistructured and a cross self-confrontation, by remote way. The results show that there is an absence/deficiency in the management of health and safety at work, which is complex because it involves several companies for which drivers provide services. It is necessary to work on this management in all sectors, create a field of regulation for the driver, who works under the pressure of production, with excessive working hours, difficult for loading and unloading, and it is necessary to offer adequate support and better working conditions, with efficient logistics and adequate service, in order to avoid the risk of illness.
\end{abstract}

Keywords: Drivers; Ergonomics; Ergology; Occupational risks; Worker's health.

\section{Resumen}

El artículo pretende dar a conocer la actividad laboral de los camioneros para comprender cómo la organización del trabajo impacta en la posibilidad de regular a estos trabajadores. El aporte teórico de la Ergonomía y Ergología se utilizó en un estudio descriptivo transversal, desarrollado en tres etapas: aplicación de cuestionario, entrevistas semiestructuradas y autoconfrontación cruzada, por vía remota. Los resultados muestran que existe una ausencia / deficiencia en la gestión de la seguridad y salud en el trabajo, lo cual es complejo porque involucra a varias empresas para las cuales los conductores prestan servicios. Es necesario trabajar en esta gestión en todos los sectores, para crear un campo de regulación para el conductor, que trabaja bajo presión de producción, con jornada excesiva, dificultad en 
la carga y descarga, y es necesario ofrecer un soporte adecuado y un mejor trabajo. condiciones, con una logística eficiente y un servicio adecuado para evitar el riesgo de enfermedad.

Palabras clave: Conductores; Ergonomía; Ergología; Riesgos laborales; Salud del trabajador.

\section{Introdução}

O sistema de transporte no Brasil é dividido em modalidades que são distribuídas conforme algumas necessidades, como capacidade de carga, tempo de deslocamento, custos, entre outros fatores (CNT, 2019). Uma dessas categorias é o transporte rodoviário de cargas, vinculado ao setor terciário que movimenta a economia do país, além de ser um complemento para outros modais de transporte, como o aéreo e marítimo (Girotto et al., 2020, p. 1012). Os sujeitos de pesquisa deste estudo são os motoristas de veículos de cargas em geral, que segundo a Classificação Brasileira de Ocupações, pertencem à classe de caminhoneiro autônomo (rotas regionais e internacionais), e têm na descrição das suas atribuições: transportar, coletar e entregar cargas em geral (Brasil, 2002).

O transporte rodoviário é um meio flexível de entregas, se comparado por exemplo, às malhas ferroviárias, por possibilitar entregas de forma rápida e direta, mas apresenta muitos problemas, como a falta de manutenção das rodovias, as condições de tráfego inseguras, fluxo muito alto de veículos e estrutura inadequada (Bezerra, 2013, p. 20). De acordo com resultados da pesquisa realizada em 2019 pela Confederação Nacional de Transporte (CNT), 59\% da extensão das rodovias avaliadas apresentam problemas de pavimento, sinalização e geometria, enfatizando ainda que a qualidade das rodovias agravou no ano anterior à pesquisa (CNT, 2019).

Sendo o modal rodoviário o mais utilizado no país, as condições das rodovias impactam diretamente nos custos do transporte, com manutenções mais caras, aumento no tempo de viagem, além do risco de acidente devido à irregularidade das estradas (CNT, 2019). Segundo a Organização Mundial da Saúde (OMS), os acidentes de transporte são responsáveis por um conjunto significativo de óbitos e lesões. O setor de transportes é responsável por empregar milhões, e no Brasil há mais de 1,1 milhão de veículos registrados para transporte de cargas em transportadoras e cooperativas (ANTT, 2019).

Obras de infraestrutura inacabadas, estradas sem pavimentação, má gestão de recursos e poucos investimentos são fatores que interferem diretamente nos custos de logística - as crises reforçam essa fragilidade dos problemas de gestão existentes (Trinquet, 2010, p. 11). Para Bezerra (2013, p. 20), a rotina de trabalho dessa classe é tida em vários estudos como intensa e irregular, em que o caminhoneiro precisa prever e se antecipar a determinadas situações, saber quanto tempo pode parar para almoçar, lanchar, abastecer e dormir. Como citado por Trinquet (2010, p. 11), “o trabalho é uma necessidade para o homem", e pode tornar-se penoso devido às condições impostas. Essas condições impostas pelo trabalho afetam a sua qualidade de vida, aumentando o risco de certos tipos de adoecimentos (Bezerra, 2013, p. 29).

Sabe-se que os riscos ocupacionais aos quais os caminhoneiros estão expostos são os mais diversos, como vibração de corpo inteiro, ruído, calor, riscos biológicos, risco químico e de acidente. Mas há outros aspectos que devem ser analisados, como os riscos psicossociais decorrentes do trabalho, que ainda são pouco conhecidos ou externados devido à dificuldade de mensuração dos mesmos (Fernandes \& Pereira, 2016, p. 2).

A organização do trabalho é importante por gerir as atividades, e uma vez que essas concepções são mal organizadas e precárias, a regulamentação do processo se torna instável. Em sua revisão de literatura, Fernandes e Pereira (2016, p. 11), constataram que uma má gestão tem efeitos negativos diretos nas relações psicossociais, causando o aumento do nível de estresse e alteração de conduta nos indivíduos, seja ela de forma emocional, cognitiva ou fisiológica, impactando na possibilidade de gestão da carga de trabalho dos motoristas (Fonseca et al., 2021, p. 7).

Por ser um estudo relevante na área de saúde e segurança, devido à escassez de pesquisas que abordam os riscos invisíveis envolvidos nesse setor (Fernandes \& Pereira, 2016, p. 2), o artigo propõe auxiliar na elaboração de medidas para melhorar a saúde e a segurança desses trabalhadores, servir de orientação na reestruturação da organização de trabalho, além 
de ser uma base para pesquisas futuras na área. Os objetivos do estudo, portanto, são levantar os riscos do trabalho do motorista profissional de carreta, avaliar seus impactos sobre a qualidade do serviço e produtividade e as (im)possibilidades de regulação da saúde e segurança no contexto analisado.

\section{Referencial Teórico}

A OMS (1946) define saúde como "uma situação de bem-estar físico, mental e social", ou seja, um equilíbrio de todas as partes e os fatores sociais são condicionantes e determinantes da relação saúde/doença (LEI 8080/1990). E a saúde no trabalho exige condições favoráveis para que o trabalhador possa realizar suas atividades de forma segura (Morais \& Borges, 2017, p. 202). A Lei do Caminhoneiro, Lei 13.103/2015, traz, entre outros pontos, os direitos do motorista, que tem a fiscalização de sua jornada de trabalho e horas de descanso regidas pela Constituição Federal. Apesar disso, tais fiscalizações não acontecem, e os acordos não são cumpridos, muitas vezes eles dirigem acima do limite para cumprir prazos e metas (Morais \& Borges, 2017, p. 212).

Segundo a nova lei, a jornada de trabalho do caminhoneiro fica estabelecida em 8 horas diárias, em que o motorista não pode dirigir por mais que 5 horas e meia ininterrupta, tendo pausas de descanso de trinta minutos, levando em consideração o número de horas extras permitidas, de 2 a 4 horas no máximo, com intervalo de 8 horas de descanso, sendo compreendido como tempo de trabalho, o tempo em que o motorista está por conta da empresa (BRASIL, 2015). A jornada de trabalho diária dos motoristas de caminhão é longa e, na maioria das vezes, ultrapassa os limites de horas, o que compromete o período de sono e descanso, e impacta na sua saúde física e mental (Penteado et al., 2008, p. 40).

Grandes jornadas de trabalho, prazos curtos, fretes baratos, faz com que tenham que trabalhar além do seu limite e tentar adequar a sua rotina e dinâmica de trabalho, segundo as suas experiências individuais. Mas a organização não interpreta os indivíduos de forma singular e não tem conhecimento de que cada um tem sua tomada de decisão baseada nos seus próprios limites e competências, uma vez que segundo Trinquet (2010, p. 100), há sempre mais de uma forma de realizar a atividade, em que a verdade não existe de forma imutável. Assim faz-se necessário centrar nossa avaliação na atividade, e não no prescrito. Nesse sentido, conhecer o trabalho coletivo de uma organização é fator determinante no processo de regulação de cada indivíduo (Pereira et al., 2017, p. 33).

O período de trabalho do motorista é considerado aquele em que ele está dirigindo, não sendo considerado o tempo em que está esperando a carga e descarga do seu transporte ou as pausas de descanso (BRASIL, 2015). No entanto, para a maioria, o trabalho se estende desde o momento em que saem de casa, até o momento que retornam para suas casas (Bezerra, 2013, p. 57). Segundo Cavagioni (2009, p. 1269), a rotina dos motoristas de caminhão pode resultar em fatores predisponentes à hipertensão arterial pelo aumento de adrenalina, noradrenalina e cortisol, sendo uma resposta fisiológica ao estresse.

Segundo a Norma Regulamentadora NR 17, as condições de trabalho devem ser adequadas às particularidades das atividades desenvolvidas no ambiente de trabalho, para cada posto de trabalho em específico, sendo as posturas do corpo dependentes das exigências, físicas e psicológicas, feitas pela atividade (Penteado et al., 2008, p. 40). A organização do trabalho deve ser responsável por gerenciar a carga de trabalho utilizando mecanismos de regulação para evitar o adoecimento do indivíduo (Norma Regulamentadora 17, 1978).

Vários fatores agravam a situação do motorista, como a inadequação do veículo, falta de manutenção e revisão, ausência de equipamentos de proteção individual, caracterizando riscos de acidentes. Além destes, estão presentes os riscos psicossociais, decorrentes de falhas na organização do trabalho, tendo efeitos negativos em níveis psicológico, físico e social (EU-OSHA, 2020). O desgaste profissional, envelhecimento precoce, vícios oriundos da profissão, sobrecarga sobre o organismo, perturbação do ritmo biológico do indivíduo além de danos psíquicos são citados por Daniellou (2010, p. 25) como graves problemas a serem enfrentados pelas organizações de trabalho. 
Camelo e Angerani (2008, p. 233) citam o conceito de riscos psicossociais:

"Os riscos psicossociais são distribuídos em categorias relacionadas ao contexto do trabalho, ou ao conteúdo do trabalho. O contexto do trabalho seria: a cultura e a função organizacional; função ou papel na organização; desenvolvimento de carreira; decisão e controle do relacionamento interpessoal no trabalho e interface trabalhofamília. E, quanto ao conteúdo do trabalho, se relaciona o ambiente e o equipamento de trabalho; planejamento de tarefas; carga e ritmo de trabalho e esquema de trabalho. Todas essas questões são, de alguma forma, responsáveis por problemas de saúde adquiridos por funcionários em suas atividades laborais. (Camelo; Angerani, 2008, p. 233).”

É abordado por Schwartz (2010, p. 42) que as questões epistemológicas da atividade de trabalho referem-se à diferença entre o trabalho formal (estabelecido pelas normas) e o informal, ao conceito da atividade, que é incorporado aos saberes do sujeito e à sua capacidade de gerir suas atividades. Ainda nesse contexto observa-se que as normas são incapazes de prever as variabilidades do meio, fazendo com que o trabalhador tenha que adaptar o seu trabalho constantemente. Para Durrive (2011, p. 54), o ato de trabalhar implica nas observações acerca de novas situações e na criação de estratégias nesse meio, onde as atividades podem trazer valores positivos ou negativos.

Sendo a atividade a realização da tarefa de outra forma, pode-se dizer que a realização do trabalho é consequência das escolhas do trabalhador no seu cotidiano, que às vezes são contraditórias e podem gerar algum tipo de sofrimento (Schwartz, 2010, p. 43). O cansaço, por exemplo, retarda as ações do trabalhador, e faz com que ele tenha mais dificuldade em terminar a atividade, devido à fadiga física ou mental, que às vezes nem é percebida (Daniellou, 2010, p. 35). O trabalho prescrito é visível, objeto de controle da organização, já o trabalho real não é visto e não é controlado, pois ele depende das singularidades de cada trabalhador e está relacionado aos seus valores coletivos e individuais, e todas essas especificidades do seu trabalho impactam na sua qualidade de vida (Trinquet, 2010, p. 100).

Na mesma abordagem Durrive (2011, p. 60), traz o processo de repadronização das atividades como uma forma de agir e compreender, e gerir constantemente as variáveis do meio, antecipar-se ao meio e às circunstâncias. $\mathrm{O}$ indivíduo tem no seu trabalho uma forma de construção de identidade essencial para desenvolver suas competências. Trinquet (2010, p. 95) discorresobre a dialética entre o saber constituído, que se refere ao saber técnico, e o saber investido, relacionado à competência e experiência do indivíduo, sendo importantes e complementares.

Renormalizar é gerir as variabilidades tanto organizacionais, materiais, ambientais e humanas, onde cada contexto exige uma nova estratégia de regulação (Trinquet, 2010, p. 99; Schwartz, 2010, p. 43, Pereira et al., 2017, p. 35), e o trabalhador está inserido em um processo de aprimoramento contínuo, em que ele aprende algo novo a cada nova variabilidade, e a cada nova decisão tomada. Trinquet (2010, p. 98) afirma que o fato de o trabalho não poder ser sempre previsto faz com que haja um espaço entre o que é prescrito e o que é executado. Por menor que seja, essa diferença sempre existe e é gerida da melhor forma possível pelos trabalhadores na realização da sua atividade, citada pelo autor como as "dramáticas dos usos de si”.

Durrive (2011, p. 48-49) fala sobre a ação de viver para o trabalhador em que as escolhas moldam a sua vida, de acordo com as possibilidades. Segundo ele, uma norma tem suas origens em um grupo de saberes e valores e, assim, pode ser realizada de várias formas, e conclui que essa renormalização está ligada ao fato de conhecer a situação e da experiência prévia, essa experiência transforma e enriquece o trabalhador, evidencia os saberes individuais em cada atividade. Esses saberes serão fundamentais na rotina de trabalho vivenciada pelos caminhoneiros, para determinar a forma como cada um realiza a gestão do seu trabalho, quais impactos isso traz e de que forma eles os interpretam. 


\section{Metodologia}

Trata-se de uma pesquisa qualitativa, do tipo estudo de caso, que por meio de entrevistas semiestruturadas e de autoconfrontação, via remota, com aporte teórico na Ergonomia (GUÉRIN et al., 2001, p. 1) e na Ergologia (Schwartz \& Durrive, 2010, p. 25). A Ergonomia trata das interações do homem com o meio e busca transformar o ambiente de trabalho, adequando-o ao trabalhador. Holz e Bianco (2014, p. 496) diferenciam de forma clara a tarefa e atividade, e reforçam que há uma defasagem entre o trabalho prescrito e o trabalho real, que geram as regulações diante das cargas de trabalho impostas, e que diminuem a margem de manobra do indivíduo fazendo com que ele se regule a todo momento.

Guérin et al. (2001, p. 175) trazem a ideia de transformar o trabalho para que os trabalhadores se mantenham saudáveis e a empresa alcance seus objetivos, e para isso um processo de adaptação que seja favorável para ambos os lados se faz necessário. O conceito de trabalho, que apresenta divergências entre a tarefa e a atividade resulta em regulações feitas pelos trabalhadores e, nesse contexto, faz-se necessário conhecer o processo de organização do trabalho para transformá-lo. O autor ainda reforça a complexidade em se analisar o trabalho, diante das diversidades com relação aos determinantes que estão relacionados à atividade, o saber fazer e como fazer é intrínseco a cada indivíduo.

Segundo Schwartz (2010 p. 44), a Ergologia busca aprofundar as hipóteses levantadas na Ergonomia, por meio do estudo das relações complexas de trabalho, onde o trabalho real jamais será apenas a execução de tarefas. Para Trinquet (2010, p. 94), ela "é um método de investigação pluridisciplinar", pelo fato da atividade humana ser complexa, impossível de ser analisada a partir de um único método, sendo necessário várias abordagens. De acordo com Holz e Bianco (2014, p. 496), a atividade humana é adaptável, sendo apresentada como "um projeto de melhor conhecer e, sobretudo, de melhor intervir sobre as situações de trabalho para transformá-las".

Holz e Bianco (2014, p. 496) analisam que o trabalhador se depara com variabilidades no seu ambiente de trabalho constantemente e se apropria dos seus valores e saberes, tornando-se seu próprio gestor, gerindo o seu trabalho de forma única e singular. Os autores ainda discorrem que a epistemologia acerca da Ergologia vem de uma abordagem pluridisciplinar, com o pensamento que liga todas as áreas do saber, tornando-se um ambiente de aprendizado e de profundo conhecimento. E concluem que o exercício da Ergologia é baseado nas confrontações de saberes técnicos com os saberes práticos. Trinquet (2010, p. 95) reforça que cada área de estudo avalia o trabalho de uma forma diferente, centrada no seu objetivo específico, mas que todas se complementam e são necessárias, não podendo obter-se respostas utilizando apenas uma delas. Para Pereira et al. (2017) sempre existirá uma distância, por menor que seja, entre o prescrito e o real, e que vai depender de alguns fatores individuais.

Como as hipóteses no estudo qualitativo não estão pré-estabelecidas, isso possibilita a sua construção durante as observações do contexto da atividade, tendo a oportunidade de fazer aflorar várias questões durante a pesquisa. As vantagens da pesquisa qualitativa é a possibilidade de interação com os trabalhadores, buscando perceber todos os detalhes do seu processo de trabalho, por meio de verbalizações, observações etc., permitindo captar aspectos da realidade que métodos quantitativos não conseguem mensurar e, assim, compreender os resultados individuais e subjetivos, alinhado ao ponto de vista de cada trabalhador, com uma abordagem abrangente da sua rotina.

\subsection{Os sujeitos da pesquisa}

Os sujeitos da pesquisa foram motoristas de carreta associados a uma cooperativa de uma cidade do interior de Minas Gerais. A cooperativa foi criada em 2019 e possui 29 associados, totalizando 35 carretas (alguns sócios possuem mais de uma carreta), que realizam transporte de minério e agregados, em cidades dentro do estado de Minas Gerais. Como descrito na resolução 4.799 da Agência Nacional de Transportes Terrestres: "uma Cooperativa de Transporte Rodoviário de Cargas - CTC, é sociedade simples, com forma e natureza jurídica própria, de natureza civil, constituída para atuar na prestação de serviços de 
transporte rodoviário de cargas, visando à defesa dos interesses comuns dos cooperados" (ANTT, 2015). A pesquisa busca conhecer a rotina e as condições de trabalho dos caminhoneiros, criando hipóteses sobre os problemas enfrentados, a percepção do trabalho da gestão e como isso impacta nas possibilidades de regulação dos motoristas.

\subsection{Procedimentos}

Um primeiro contato foi feito com o gestor da cooperativa, para apresentar o objetivo da pesquisa e conhecer a forma de gestão, de trabalho e sanar algumas dúvidas relacionadas ao contexto estudado. Em seguida, foi realizado um contato inicial com os motoristas para apresentação do objetivo da pesquisa e dos procedimentos que seriam realizados, bem como assinatura do Termo de Consentimento Livre e Esclarecido. Inicialmente, aplicou-se o questionário sociodemográfico, enviado online, para caracterização dos participantes. Posteriormente, foram realizadas entrevistas abertas e semiestruturadas, individualmente, com alguns motoristas, por meio de vídeo chamadas, utilização de roteiro e perguntas específicas. Foi utilizada a plataforma Google Meet licença Preemium (Google Corp, Mountain View, Califórnia, EUA) para entrevista e gravação da mesma. A transcrição das informações foi realizada através do editor de textos Google Docs, que oferece um recurso de digitação por voz. Foi feita análise de conteúdo dos dados obtidos com base na metodologia proposta, utilizando-se das verbalizações coletadas dos participantes. A coleta de dados foi realizada no período de abril a maio de 2021. Este estudo foi aprovado pelo Comitê de Ética em Pesquisa da Fundação de Ensino e Pesquisa de Itajubá (FEPI), sob o parecer no CAAE 43046820.6.0000.5094.

\section{Resultados e Discussão}

A cooperativa em análise, tem por objetivos, reduzir os custos de produção e permitir mais ganho por tonelada, firmando parcerias e promovendo a flexibilidade desses contratos entre as empresas e os motoristas, procurando sempre os melhores fretes. Além dos associados, a cooperativa conta com mais de 100 funcionários terceirizados, que não são fidelizados com a cooperativa, mas prestam serviços esporádicos, devido à alta demanda de cargas. A diretoria da cooperativa é formada por três diretores, um diretor presidente, um diretor administrativo e um diretor secretário, além de três pessoas responsáveis pelo controle fiscal efetivo e três no conselho fiscal suplente. Todos os representantes são sócios fundadores e todos os associados têm direito a voto na eleição dos representantes que ocorre a cada dois anos (não há diferença com relação aos benefícios, entre os sócios fundadores e os associados).

Todos os associados são autônomos e donos da própria carreta, sendo responsáveis pela manutenção, gastos com alimentação e combustível. A empresa ainda não possui uma garagem e os motoristas deixam suas carretas em vias públicas. Segundo o presidente, há um projeto de construção de uma garagem com dormitório, cozinha, banheiros, pátio, setor de manutenção e bomba própria de combustível - o projeto está aguardando decisão da prefeitura para ceder um terreno. A função do presidente é ser o contato das empresas com os motoristas - receber uma demanda, repassar os valores de frete e direcionar os serviços para os motoristas. Os trabalhadores são pagos por frete, pelo qual recebem $95 \%$ do valor, e $5 \%$ para o caixa da cooperativa. Quando a demanda é muito alta, os contratos são encaminhados aos terceirizados, que recebem também 95\% do valor do frete, menos um real, descontado do preço de cada tonelada.

O questionário foi realizado online - no total 30 motoristas responderam, sendo 21 associados e 9 terceirizados. As 9 respostas dos motoristas terceirizados foram descartadas por não se enquadrarem no critério de inclusão, ser associado da cooperativa. A amostra dos motoristas de carreta deste estudo, caracterizou-se, por: a maioria dos participantes eram do sexo masculino $(95,2 \%)$, com mais de 30 anos, casados $(52,35 \%)$ e com ensino médio completo $(61,9 \%)$. A maior parte também era motoristas de longas distâncias, percorrendo diariamente de $251 \mathrm{~km}$ a $500 \mathrm{~km}$. 
Tabela 1 - Distribuição dos motoristas segundo faixa etária, sexo, escolaridade e estado civil.

\begin{tabular}{|l|l|l|l|l|l|l|l|}
\hline Variável & Categoria & $\mathbf{n}$ & $\%$ & Variável & Categoria & n & $\%$ \\
\hline Idade (anos) & $20-30$ & 6 & 28.5 & Escolaridade & Ensino Médio Completo & 13 & 61,9 \\
\hline & $30-40$ & 11 & 52.5 & & Ensino Médio Incompleto & 5 & 23,8 \\
\hline $40-50$ & 4 & 19 & & Ensino Fundamental Completo & 3 & 14.3 \\
\hline
\end{tabular}

Fonte: Autores (2021).

Os motoristas de carreta passam a maior parte do seu tempo dentro dela, e acabam por torná-la parte integrante da vida pessoal, como também demonstrado por Morais e Borges (2017, p. 201). Schwartz (2010, p. 39), ao apresentar o trabalho como sendo uma dialética entre a atividade técnica e a interpretação dessa atividade, conclui que simplificar o trabalho à apenas a execução de tarefas é algo impossível.

Gráfico 1 - Quilômetros Percorridos Diariamente.

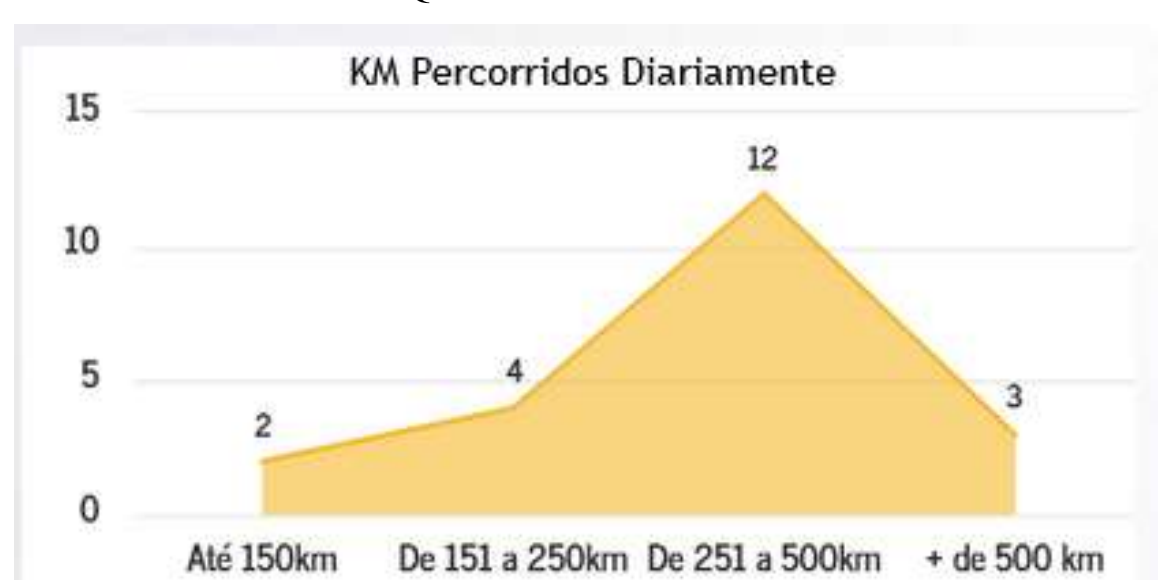

Fonte: Autores (2021).

Os motoristas de caminhão frequentemente são sujeitos a longas jornadas de trabalho, e a horários irregulares, fato também confirmado por Ulhoa et al. (2010, p. 1131). Quando questionados sobre conhecer a lei do caminhoneiro, a maioria respondeu que $\operatorname{sim}(66,7 \%)$. Apesar de a lei estabelecer horas de sono, pausas, e servir de suporte ao trabalho prescrito, na prática o trabalho real se encontra desamparado. Na pesquisa de Bezerra (2013, p. 15), é apontado que essas horas não são cumpridas e que os caminhoneiros chegam a dirigir até 18 horas por dia para cumprir os prazos de entrega. Esse tipo de estilo de vida inadequado faz com que eles tenham o consumo de álcool e fumo, por exemplo, além do sedentarismo. Ulhoa et al. (2010, p. 1132), utilizou o Self-Report Questionnaire (SRQ-20), em um estudo com 460 motoristas e verificou que 82,8\% da população estudada faziam uso de bebida alcoólica. Quando questionados sobre o uso de bebida alcoólica, apenas 33,33\% dos caminhoneiros participantes desse estudo relataram beber socialmente, resultado esse que pode servir de base para afirmar que o uso de bebida alcoólica não é sempre comum entre os caminhoneiros. 
Gráfico 2 - Horas de Sono Diárias.

\section{Horas de Sono}

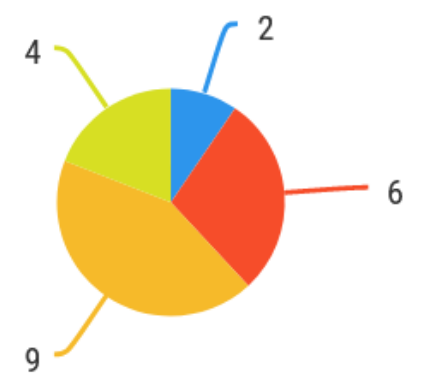

Menos de 4 horas

De 4 a 5 horas

De 5 a 6 horas

De 7 a 8 horas

Fonte: Autores (2021).

A maior parte dos trabalhadores dorme apenas 4 a 5 horas por dia (42,95\%), uma quantidade muito abaixo do ideal. $\mathrm{O}$ fato de o motorista trabalhar por contrato de trabalho deve ser levado em consideração, uma vez que precisam realizar entregas para receber, não tendo uma remuneração fixa, acabam trabalhando mais, para elevar o rendimento. Nesse aspecto, muitos não veem o seu trabalho como horas trabalhadas, mas sim como entregas realizadas e acabam excedendo seu limite, por escolha própria para cumprir os prazos estabelecidos.

Schwartz (2010, p. 43) analisa um contexto em que os trabalhadores são reféns de suas próprias escolhas e que essas escolhas geram riscos, e entende-se o processo de regulação como uma forma de orientar sua atividade da melhor maneira, isso inclui os seus recursos, capacidades e objetivos. Assim cada trabalhador tem uma reação ou posicionamento diferente diante de cada situação, isso está relacionado a sua história, conhecimento, seus critérios e sua experiência.

Gráfico 3 - Horas de Trabalho Diárias.

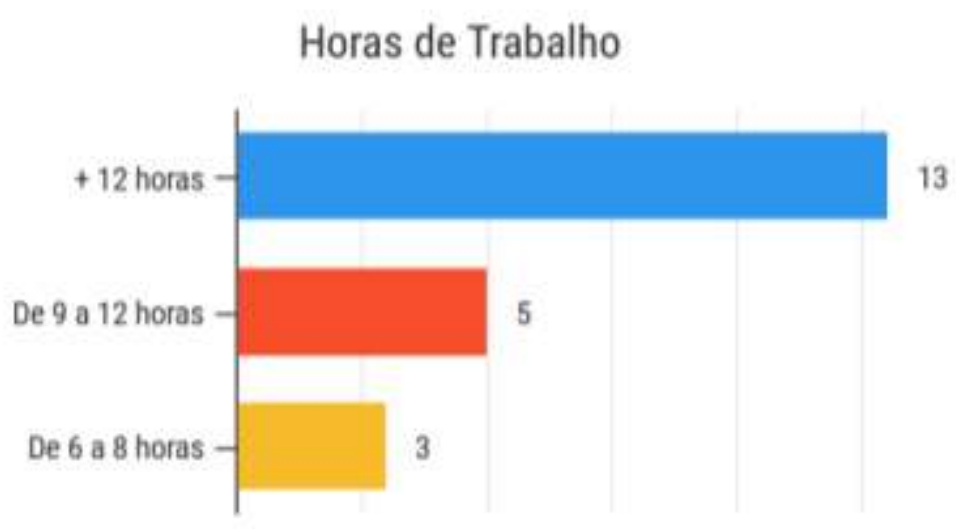

Fonte: Autores (2021).

A maioria dos motoristas dirige por mais de 12 horas por dia (61,9\%). O caminhoneiro tem que se adaptar a novas rotas de entrega, ao trânsito, condição sobre as quais não tem controle, mas afetam diretamente no prazo de entrega e, para se manter na profissão, precisam dirigir mais horas, além do estabelecido por lei (Bezerra, 2013, p. 29). 
Sobre os principais problemas apresentados, foram cansaço $(85,7 \%)$, dor nas costas $(71,4 \%)$, ganho de peso $(52,4 \%)$ e estresse (47,6\%). Segundo Daniellou (2010, p. 71) o estresse é uma resposta biológica do organismo às condições adversas, sendo dividido nos seguintes sinais: o sinal de alerta, onde tem-se uma energia concentrada, o sinal de resistência, quando o estresse ainda continua, o sinal de esgotamento, quando o organismo não reage mais e as patologias podem aparecer, pois as suas regulações biológicas já se encontram em um estágio avançado de sobrecarga. Segundo Ulhoa et al. (2010, p. 1131) distúrbios psíquicos menores (DPM) incluem sintomas como depressão, ansiedade, fadiga, irritabilidade, insônia e déficit de memória e de concentração, em seu estudo, o mesmo autor aponta a falta de literatura nesse sentido, tendo poucos estudos realizados.

Os pontos positivos mais apontados pelos motoristas foram a liberdade $(76,2 \%)$, a oportunidade de conhecer novos lugares (66,7\%), o salário (61,9\%) e a autonomia (57,1\%). A profissão tem seu significado para eles (Bezerra, 2013, p. 40) e o seu reconhecimento, seja pelos colegas, família ou pela gestão é importante, pois o trabalho, além do viés econômico, é uma forma de interação social necessária para o homem, trazendo um benefício subjetivo, que traz os seus valores e crenças" (Daniellou, 2010, p. 45-46).

Em contrapartida, os pontos negativos mais citados foram com relação ao alto custo do diesel (100\%) e ao valor baixo do frete $(95,23 \%)$. A não regulamentação dos preços do frete é um problema (Bezerra, 2013, p. 49), assim como a falta de uma organização funcional que atenda aos determinantes dessa atividade (Daniellou, 2010, p. 84). O suporte de uma organização é importante por fazer um controle das atividades, regras formais e uma melhor gestão de horários, fretes, formas de repassar instruções e informações, além de focar nos estados de saúde dos trabalhadores. Outros pontos levantados são com relação às estradas mal conservadas $(90,5 \%)$, a falta de suporte nas estradas $(76,2 \%)$ e a falta de respeito pela profissão $(80,9 \%)$.

Um ponto importante a ser considerado é com relação ao tempo de profissão. A maior parte tem mais de 10 anos de profissão (47,6\%), a outra parte está dividida na faixa de 5 a 10 anos (28,6\%), e menos de 5 anos (23,8\%). Algumas variabilidades são irrelevantes para o motorista, como o material que ele vai carregar, a empresa para qual vai prestar o serviço. Outros já são mais relevantes, como as condições do tempo, a distância, o preço do frete e o prazo. Para Daniellou (2010, p. 89), as situações interferem no comportamento do indivíduo.

Em seguida, foram realizadas entrevistas semiestruturadas para compreender a rotina de trabalho, quais dificuldades o motorista de carreta enfrenta e de que forma ele reage diante das imprevisibilidades. No total, quinze motoristas participaram das entrevistas, realizadas por chamada de voz, de forma individual, com duração aproximada de quinze minutos cada. As conversas foram gravadas, com autorização dos participantes, e depois transcritas, para análise das verbalizações. Como cada indivíduo enxerga o trabalho e lida com situações de trabalho de forma diferente (Daniellou, 2010, p. 33-36), é imprescindível ter as verbalizações de diferentes caminhoneiros e observar as semelhanças e divergências das informações com relação às falas de cada um, procurando entender quais as condutas profissionais e as estratégias em comum de regulação.

Há opiniões contraditórias com relação ao salário, alguns relatam estarem satisfeitos, para a categoria profissional e o nível de formação, outros já dizem ter que trabalhar demais para conseguir ganhos mais altos e que a profissão não é valorizada. Percebe-se que essa visão sobre o seu trabalho varia com relação ao tempo de profissão, uma vez que os que manifestaram estar satisfeitos já trabalham há mais de dez anos na profissão. Os que possuem menos tempo de profissão, supostamente esperam melhores condições de remuneração e melhores oportunidades de crescimento. A satisfação do trabalhador depende de sua percepção sobre as condições de trabalho, sobre o que ele entende por controle e autonomia (Ulhoa et al. 2010, p. 1135).

"Somos quem move o Brasil e, mesmo assim, não temos valor. Tanto é que eu acho que deveríamos nos enquadrar no quadro de prioridades pra vacina do Covid 19. Afinal não paramos sequer um dia desde o início da pandemia, e se pararmos nem vacina tem (CA-01)." 
“...eu não tenho uma rotina fixa, às vezes fico 15 dias sem ir em casa, às vezes vou todos os dias...às vezes dirigi por mais de 24 horas direto, e meu trabalho não é valorizado... (CA-01)."

Ao serem questionados sobre como é a rotina de trabalho, quais as dificuldades e riscos, a maioria dos participantes se queixam dos horários irregulares de trabalho, da falta de horário fixo para almoçar, tomar banho e dormir, do risco de acidente e de violência. Reclamam de ter sempre que se adaptar aos horários de acordo com a empresa para qual estão prestando serviço e que as normas e regras mudam constantemente. $\mathrm{O}$ trânsito caótico é mencionado várias vezes por todos os participantes, fator que acentua o risco de acidente, além da lentidão, que provoca longas filas e atrasa o prazo de entrega, o excesso de velocidade dos outros veículos leves e as irregularidades da pista contribuem para a situação.

"Às vezes almoço 10 horas, às vezes 14 horas, nunca se sabe. Se o caminhão quebra ou tem trânsito lento, pior ainda...chego na empresa e já tem uma fila pra descarregar enorme... (CA-02)."

Alguns motoristas relataram já terem sofrido algum tipo de acidente de trabalho (33,3\%), sendo a maioria acidentes com danos pessoais leves ou acidentes materiais. Alguns exemplos citados foram queda de altura, ao "deslonar" o caminhão, tombamento da carreta por bascular em terreno irregular ou por carga mal posicionada, colisão e atropelamento. Para cumprir os prazos determinados eles fazem uso de substâncias estimulantes, para combater o sono, evitando assim paradas e dirigindo por mais horas. Mas é relatado por muitos que os efeitos são severos no dia seguinte e que, se não houver um controle, pode resultar em algum tipo de vício ou dependência química. Outro problema relatado é a falta de local para estacionar o caminhão, muitos o fazem nas portas de casa, por não ter uma garagem para isso e acabam relatando roubos de peças e combustível.

“...tentaram me obrigar a parar o caminhão na estrada de madrugada, usaram objetos na pista, quando percebi que era um assalto eu fugi e eles vieram atrás, felizmente consegui despistar. Já roubaram 2 baterias de um caminhão que estava na porta da minha casa (CA-03)."

“...quando transportava combustível, em São Paulo, me levaram para um canavial, colocaram em um carro e um capuz na minha cabeça, fiquei rodando com eles até no outro dia cedo. Me liberaram em uma estrada de terra onde andei por algum tempo até a cidade e chamei a polícia ... pouco depois foi localizada a carreta sem a carga (CA04)."

Schwartz (2000, p. 41) diz que a atividade humana está sujeita a um contexto de julgamento de procedimentos, num processo de renormalizações. Para Durrive (2011, p. 53), o homem se vê diante de um confronto com o que o trabalho exige dele e, em contrapartida, do que ele exige de si, de forma a "compreender a atividade humana" como uso de si. O trabalhador não tem outra alternativa senão se adaptar ao ritmo e às condições de trabalho, normalizando-se, antecipando o seu agir de acordo com as demandas do trabalho, fazendo aflorar a sua individualidade na forma como cada um interpreta as normas (Durrive, 2011, p. 54).

“...tem dia pra sair de casa, mas não tem dia certo pra voltar... a gente não encontra restaurante bom pra comer, já tentei comer uma comida mais saudável, mas acho e tenho engordado muito, sem contar que não tem banheiro limpo, e as pessoas são muito mal educadas na estrada, principalmente os motoristas de carro (CA-05)." 
Há necessidade de analisar o trabalho pensando em toda sua complexidade, abordando o individual e coletivo, as diferenças e semelhanças impostas no contexto de "fazer" e dos seus valores, alinhando o que é imposto pelo trabalho e o que é idealizado pelo trabalhador (Schwartz, 2010, p. 41). Complementado ainda pelo autor, que as atividades são redefinidas pelos sujeitos a todo momento, com base no "aqui e agora", e essa atividade jamais poderá ser medida, categorizada ou modelizada.

"Eu tento andar na velocidade da via, respeitar o limite do meu cansaço, mas isso aqui é uma arma, e a gente não é valorizado, tenho que trabalhar muito, muito além do que gostaria (CA-06)."

"Pra mim um dos maiores problemas é a polícia pegando no pé da gente, pra pesar na balança, e não deixar passar o limite da carga... muitas vezes temos que "molhar a mão do cara" pra ele deixar a gente seguir viagem... eu preciso transportar mais porque eu ganho por tonelada (CA-06)."

Como descrito por Daniellou (2010, p. 9), o trabalho não se restringe apenas a uma execução de procedimentos e as variabilidades estão presentes a todo momento, fazendo com que o indivíduo tenha que adaptar seu modo operatório a elas, o que leva em consideração as suas experiências pessoais. Apesar das normas tentarem se antecipar às situações rotineiras de trabalho, elas se baseiam apenas na teoria, e na realidade, o contexto se forma por meio do encontro de normas com o processo de gestão contínua dessas situações pelo indivíduo, sendo a repetição das tarefas um modelo imperfeito criado pela sociedade (Schwartz, 2010, p. 44).

O tempo de espera para carregar e descarregar, que não é contado como tempo efetivo de trabalho, os altos custos de manutenção, que consequentemente diminuem os lucros dos fretes, a limitação da interação familiar e social, faz com que o trabalhador realize regulações a todo momento, seja ultrapassando um limite de velocidade, parando em local proibido, extrapolando o limite de horas de sua jornada de trabalho, fatores os quais as normas não são capazes de antecipar (Schwartz, 2010, p. 46). No final das contas eles desenvolvem alguns transtornos psíquicos decorrentes dessas regulações, como insônia, depressão, estresse, entre outros.

"Temos que ter uma fiscalização do órgão público sobre o valor do frete, pneus e peças pra reposição ou manutenção, pois, no presente momento, está superfaturado e inviável até uma manutenção mais detalhada, ou seja, uma segurança melhor para todos, exemplos: pneus carecas, luzes de sinalização e demais manutenções preventivas (CA-07)."

É descrito por Trinquet (2010, p. 96), "que há uma distância entre o trabalho prescrito do trabalho real", e essa dialética é reforçada por Schwartz (2010, p. 40) e Daniellou (2001) com duas abordagens: a do trabalho visível e interpretável seguindo técnicas, normas e ferramentas, regras e prescrições, conhecimentos técnicos e científicos e o trabalho real que engloba a gestão, única e singular de todo esse processo. A norma estabelece horários para dirigir, descansar, pausas para comer e dormir, mas a realidade que eles enfrentam é totalmente diferente.

"Às vezes não consigo fazer todas as refeições no dia, já me alimentei uma única vez no dia" ... as empresas têm um descaso com a gente, trata mal, não tem suporte nenhum, nem um tratamento adequado. Todo lugar que a gente vai tem horário pra tudo, menos pra gente almoçar e descansar (CA-08)." 
A falta de um suporte melhor nas estradas, além de manutenção e sinalização adequada nas rodovias, que apresentam condições de risco diárias. Uma simples orientação aos motoristas de veículos leves também é citada, para que mantenham uma postura preventiva, pois muitos não respeitam as sinalizações da via e ultrapassam em local proibido, entram entre uma carreta e outra, e não têm a noção do espaço necessário para uma carreta parar com segurança. Na opinião dos motoristas, há uma enorme falta de conscientização dos motoristas e a necessidade da realização de campanhas falando sobre o assunto.

“O tempo que eu demoro pra parar é muito maior que o de um carro pequeno, eles entram na minha frente, freiam de uma vez e a gente quase bate neles, temos que manter uma distância segura, mas nem sempre conseguimos (CA-06).”

Para compreender alguns assuntos levantados durante as entrevistas individuais, foi realizada uma autoconfrontação cruzada, com a participação de dois motoristas que se dispuseram a participar. Essa etapa foi realizada por meio de uma chamada de voz, que foi gravada com consentimento dos participantes, trazendo questões relacionadas aos principais pontos levantados nas entrevistas individuais: a falta de suporte nas empresas e a falta de um sistema eficiente de logística e de segurança.

Durante a autoconfrontação ficou evidente a falta de profissionalismo das empresas com relação aos caminhoneiros em que a maioria não tem um atendimento com respeito e educação, utilizam os caminhões de depósito e os fazem esperar por horas para descarregar, sem poder sair da empresa, tendo os telefones confiscados. Reclamam do desrespeito, da falta de procedimento nas empresas, onde eles têm que se adaptar a um novo procedimento constantemente. O tempo de carregar e descarregar não é controlado, às vezes demora duas horas, outras vezes dois dias, não há um processo de logística eficiente que considere as necessidades e dificuldades relacionadas pelos motoristas, por exemplo, ao trânsito lento e as pausas que eles precisam fazer. Se perdem a hora de descarregar eles precisam esperar até o outro dia, como não tem salário fixo e dependem dos fretes, esse tempo não é considerado, gerando prejuízo.

“Eles passam os treinamentos sobre segurança, mas parece que é só pra eles, pra gente não...levaram meu telefone, em situação de emergência eu ligo pra quem? Não tem nenhum telefone fixo a nossa disposição pra isso...nem equipamento de segurança nos dão...um desrespeito sem tamanho (CA-05)."

"Fiquei 4 horas esperando para descarregar dentro da empresa, sem almoço, sem lanche, sem poder descer do caminhão, tem filas enormes todos os dias, dependemos muito de terceiros pra esse processo de carga e descarga... (CA-05)."

O trabalho humano é compreendido de formas diferentes em cada grupo de motoristas, sendo a percepção de cada um do seu trabalho formada através de um conjunto de valores, interligados pelo nível micro do trabalho e o macro da vida social, de modo que as histórias e experiências do trabalhador refletem e interferem na sua rotina de trabalho (Holz \& Bianco, 2014, p. 499). A problemática sobre a falta da gestão da segurança e da gestão de pessoas no setor caminhoneiro é um ponto importante, que deve ser levado em consideração no processo de melhoria das condições de trabalho (Morais \& Borges, 2017, p. 203). A atividade de colocar e retirar a lona do caminhão (“deslonar") é realizada, na maioria das vezes, pelos motoristas, que relatam uma grande contradição: não podem subir para realizar essa atividade nos limites da empresa, porque ultrapassa dois metros de altura e é obrigatório utilizar cinto de segurança, mas são orientados a saírem das dependências da empresa para realizar a atividade, fato esse que entra em conflito com as questões de saúde e segurança que são defendidas pelas empresas, em treinamentos e procedimentos que eles mesmos apresentam aos caminhoneiros, toda vez que entram em uma nova 
empresa.

“Os locais de acesso, banheiro, lugar para almoçar, não tem suporte nenhum. Cobram muito sobre segurança da gente, mas não nos dão nada...por exemplo, dentro da empresa eu não posso subir no caminhão porque posso cair, do lado de fora não tem problema se eu me machucar...isso é uma falta de respeito total, chega a ser desumano (CA02)."

“...eu entro no caminhão pra aguardar pra descarregar, e já é onze da noite, tento dormir e a cada meia hora o vigia bate na porta pra eu arredar o caminhão pra frente, dez metros, e assim vai a noite toda...eu não durmo, e ainda tenho que escutar reclamação dele... merecemos mais respeito, o mínimo que merecemos (CA-02).”

Por se tratar de um setor central para a economia do país, principalmente os que trabalham com matéria prima e insumos, é uma profissão que demanda muito do trabalhador, com um ritmo intenso de trabalho, ao qual ele está sujeito a vários constrangimentos, além de ser uma profissão marginalizada socialmente. Muitos se queixam por não receberem o respeito que deveriam. A atividade de carregar a carreta é realizada pelo operador da empresa para a qual vão prestar serviço, mas na maioria das vezes, o motorista não pode descer do caminhão e acompanhar o processo, se o operador for inexperiente, por exemplo, ele não distribui a carga corretamente e cria um problema para o motorista, que não pode conferir a carga e nem estabelecer a forma como gostaria que fosse feito. “A preocupação deles é só com a área interna deles, do lado de fora não ligam pra gente...eles carregam a carga de
qualquer forma, fica mal distribuída...dependendo a gente tomba numa curva ou descarregando, e isso a empresa
não se responsabiliza...não podemos subir, não podemos conversar com operador... a gente fica trabalhando às cegas
(CA-02).”

"eu acho que se a gente não pode nem conversar com eles, pelo menos eles poderiam dar um treinamento, orientar eles sobre como fazer, dos riscos que a gente tem quando a carga fica mal posicionada... (CA-05).”

Os dados e verbalizações levantadas têm relevância por apresentarem um objetivo diferente da maioria das pesquisas, por meio de uma perspectiva de abordagem centrada nos riscos invisíveis nos quais o trabalhador está exposto. A maioria dos pesquisadores tem seus objetivos centrados em fatores de risco como a obesidade, hipertensão, diabetes e sedentarismo, físicos e ergonômicos aos quais os trabalhadores estão sujeitos. Por outro lado, neste estudo foram desvelados os problemas que uma má gestão pode causar no processo de regulação desses motoristas, eternizando uma rotina de trabalho, que afeta na sua qualidade de vida. Este estudo busca entender a perspectiva do caminhoneiro sobre a sua rotina e como ele enxerga o seu trabalho, trazendo questões importantes para uma análise mais profunda sobre o processo de gestão e como isso pode ser trabalhado.

\section{Conclusão}

Os caminhoneiros sofrem com os desgastes causados pelas rotas e, para se adaptarem a essa realidade, muitos realizam mais viagens, em menos tempo, para compensar as perdas, em busca de um salário melhor, além de vários fatores externos, como preços de diesel, pedágios, preço do frete imposto pelas empresas, que interferem no contexto. Apesar da 
quantidade de participantes não representar o todo, muitos caminhoneiros têm essa realidade de trabalho e sofrem com essas mesmas condições, com a falta da valorização da profissão, que é tida por muitos como negligenciada pelo sistema.

Apesar de existirem leis, não há uma regulamentação rígida e os caminhoneiros continuam a ter suas longas jornadas ininterruptas e sem salário fixo; essas longas esperas para carregar e descarregar e o trânsito intenso impactam no seu salário diretamente. As questões de saúde e segurança devem ser abordadas entre os motoristas e algumas medidas podem ser implantadas, como treinamentos, campanhas sobre saúde e segurança e conscientização das empresas sobre a necessidade de um sistema de gestão integrada que ofereça condições mínimas de segurança e higiene aos caminhoneiros durante a etapa de carga e descarga.

O estudo evidenciou que não há apenas uma má gestão do trabalho na cooperativa em si, mas também problemas de gestão em cada uma das empresas para as quais eles prestam serviços. Eles enfrentam uma nova realidade diariamente, que traz novas necessidades de adaptação, novos procedimentos e normas, o que não permite uma regulação do trabalhador, ele acaba por não conhecer a sua margem de manobra, por não ficar tempo suficiente em cada local de trabalho, mudando constantemente, o que os impossibilita de ter uma rotina adequada de trabalho, isso contribui para o desenvolvimento de fatores de riscos psicossociais. E ficou claro que os riscos invisíveis da profissão estão relacionados à falta de suporte que eles encontram, resultado de uma má gestão desse processo de trabalho, que impacta diretamente esses trabalhadores que se sentem desmotivados e desvalorizados.

$\mathrm{O}$ trabalho interfere na qualidade de vida e as percepções relatadas na pesquisa deixam claro suas expectativas sobre as melhorias do processo, segurança, saúde e qualidade de vida na sua atividade profissional e há uma necessidade constante e geral de reconhecimento e valorização. É necessário ampliar o campo de regulação dos motoristas, fiscalizar os horários, criar um novo modelo de gestão de trabalho que possa oferecer uma assistência adequada e condições melhores de trabalho, além de uma logística mais eficiente e estruturada, que corrobore para um ambiente mais saudável no âmbito psicossocial e que seja implementado em todas as empresas que utilizam os serviços dos caminhoneiros.

Sugere-se para trabalhos futuros realizar uma pesquisa que compare a população dos motoristas de carreta autônomos com a população de motoristas regidos pelo regime CLT, avaliando quais os pontos divergentes e convergentes existem entre as classes.

\section{Referências}

ANTT (2015). Registro Nacional de Transportes Rodoviários de Carga. Brasil, 2014. Agência Nacional De Transportes Terrestres. http://www.antt.gov.br/index.php/content/view/4929/RNTRC__Registro_Nacional_de_Transportadores_Rodoviarios_de_Cargas.html.

Bezerra, K. A. (2013) Significados atribuídos ao trabalho por caminhoneiros dos setores formal e informal da cidade de Parnaíba-PI. Monografia (Graduação em Psicologia), Universidade Federal do Piauí, p. 20-57. http://www.repositorio.ufc.br/bitstream/riufc/19340/1/2016_dis_kabezerra.pdf.

Brasil. (1990). Lei N ${ }^{\circ}$ 8.080. Lei Orgânica da Saúde - Dispõe sobre as condições para a promoção, proteção e recuperação da saúde, a organização e o funcionamento dos serviços correspondentes. https://www.planalto.gov.br/ccivil_03/leis/18080.htm.

Brasil. Ministério do Trabalho e Emprego (2002). Classificação Brasileira de Ocupações, Brasília, DF. http://portal.mte.gov.br/portal-mte/.

Brasil. (2015). Departamento Nacional de Infraestrutura de transportes. Brasília, DF, Brasil. http://www.transportes.gov.br.

Brasil. Ministério Do Trabalho. (1978). Norma regulamentadora no 17 - Ergonomia. http://www.guiatrabalhista.com.br/legislacao/nr/nr17.htm. Aprovada pela portaria 3.214 de 08 de junho de 1978 .

Cavagioni, L. C. (2006). Perfil dos riscos cardiovasculares em motoristas profissionais de transporte de cargas da Rodovia BR-116 no trecho Paulista-Régis Bittencourt. Tese (Mestrado em Enfermagem na Saúde do Adulto) - Escola de Enfermagem da Universidade de São Paulo, São Paulo, p. 1267-1271. https://teses.usp.br/teses/disponiveis/7/7139/tde-15012007-150411/publico/Luciane_Cesira.pdf.

Camelo, S. H. H., \& Angerami, E. L. S. Riscos psicossociais no trabalho que podem levar ao estresse: uma análise da literatura. (2008). Rev. Ciência, Cuidado e Saúde, 2(7), 232-240. http://www.periodicos.uem.br/ojs /index.php/CiencCuidSaude/article/view/5010/3246.

CNT. (2019). Confederação Nacional de Transporte. Pesquisa CNT de Rodovias. https://pesquisarodovias.cnt.org.br/downloads/ultima versao/resumo_de_imprensa.pdf. 
Daniellou, F., Simard, M. E \& Boissières, I. (2010). Fatores Humanos e Organizacionais da Segurança Industrial: um estado da arte. Traduzido do original Facteurs Humains et Organisationnels de la Sécurité Industrielle por Rocha, R., Lima, F. e Duarte, F. Cadernos da Segurança Industrial, ICSI, Toulouse, França 9-85. http://www.icsi-eu.org.

Durrive, L. (2011). A atividade humana, simultaneamente intelectual e vital: esclarecimentos complementares de Pierre Pastré e Yves Schwartz. Rev. Trabalho, Educação e Saúde, 9, 46-67. https://www.scielo.br/pdf/tes/v9s1/03.pdf.

Estrela, C. (2018). Metodologia Científica: Ciência, Ensino, Pesquisa. Editora Artes Médicas.

EU-OSHA (2020). Riscos psicossociais e estresse no trabalho. Agência Europeia Para A Segurança E Saúde No Trabalho, EU-OSHA. https://osha.europa.eu/pt/themes/psychosocial-risks-and-stress.

Fernandes, Cláudia, Pereira, Anabela. (2016). Exposição a fatores de risco psicossocial em contexto de trabalho: revisão sistemática. Rev. Saúde Pública, 50(24), 2-11.

Fonseca, M. L. F., Mendes, J. C. L., Moraes, G. F. S., \& Mendes, D. P. Estratégias individuais e coletivas de gestão dos serviços de higienização e limpeza no setor de hemodiálise de um hospital de referência macrorregional. Research, Society and Development, 10, 7.

Girotto, E., et al. (2020). Comportamentos alimentares de risco à saúde e fatores associados entre motoristas de caminhão. Rev. Ciênc. saúde coletiva, 25(3), 1011-1023. http://www.scielo.br/scielo.php?script=sci_arttext\&pid=S141381232020000301011\&lng=en\&nrm=iso.

Guérin, F., Laville, A., Daniellou, F., Duraffourg, J., \& Kerguelen, A. (2001). Compreender o trabalho para transformá-lo: A prática da Ergonomia. Fundação Vanzolini, Edgard Blücher, 1-175.

Holz, E. B., \& Bianco, M. de F. (2014). Ergologia: uma abordagem possível para os estudos organizacionais sobre trabalho. Cad. EBAPE.BR, 12, 494-512.

Lopes, G., Russo, L., Chaves, P., \& Fiorini, A. C. (2007). Estudo da audição e da qualidade de vida em motoristas de caminhão. Rev. CEFAC, 9(4), 532-542.

Morais, M. S. S., \& Borges, E. M. F. (2017). Uma análise sobre os riscos ocupacionais dos motoristas de caminhão. Rev. Científica FacMais, Volume. IX, Número 2, p. 199-225.

Organização Mundial Da Saúde (OMS). (1946). Constituição da Organização Mundial da Saúde. Biblioteca virtual. http://www.direitoshumanos.usp.br/index.php/OMS-Organiza\%C3\%A7\%C3\%A3o-Mundial-da-Sa\%C3\%BAde/constituicao-da-organizacao-mundial-dasaude-omswho.html.

Penteado, R. Z., Gonçalves, C. G. O., Costa, D. D., \& Marques, J. M. (2008). Trabalho e Saúde em Motoristas de Caminhão no Interior de São Paulo. Rev. Saúde e Sociedade, 17(4), 35-45.

Pereira, A., Mendes, D., \& Moraes, G. (2017). Do prescrito ao real: a imprevisibilidade e a importância do trabaho coletivo em um centro de usinagem de uma empresa metal-mecânica do interior do Estado de Minas Gerais. Laboreal, 13 (1), 24-38. http://dx.doi.org/10.15667/laborealxiii0117ep.

Silva, L. F., \& Mendes, R. (2005). Exposição combinada entre ruído e vibração e seus efeitos sobre a audição de trabalhadores. Rev. de Saúde Pública, 39(1), $9-17$.

Schwartz, Y. (2010). A experiência é formadora? Rev. Educação \& Realidade, 35(1), 35-48. https://core.ac.uk/download/pdf/303969355.pdf.

Schwartz, Y., \& Durrive, L. (Orgs.). (2010). Trabalho e ergologia: conversas sobre a atividade humana. Niterói: Ed.UFF.Schwartz, Y. (2000). Trabalho e uso de si. Rev. Pro-Posições, 11(2), 34-50.

Trinquet, P. (2010) Trabalho e Educação: o método ergológico. Rev. HISTEDBR On-Line, Campinas, n. especial, 93-113. https://periodicos.sbu.unicamp.br/ojs/index.php/histedbr/article/view/8639753/7318.

Ulhoa, M. A., et al. (2010). Distúrbios psíquicos menores e condições de trabalho em motoristas de caminhão. Rev. Saúde Pública, 44(6), 1130-1136. http://www.scielo.br/scielo.php?script=sci_arttext\&pid=S003489102010000600019\&lng=en\&nrm=iso. 